\title{
OBSERVATIONS ON THE RESISTANCE OF TIGRIOPUS FULVUS (FISCHER) TO CHANGES IN TEMPERATURE AND SALINITY
}

\author{
By M. R. RANADE \\ Marine Biological Station, Port Erin
}

(Text-figs. I and 2)

The harpacticid copepod Tigriopus fulvus (Fischer) has a wide distribution along the European coast, generally occurring in pools at or above high-water mark, where the environmental conditions are liable to sudden and extreme changes. Fraser (1936), while studying the life history and ecology of T. fulvus, has quoted Issel (I9I4): 'A few weeks of periodical observations of the pools since 1912 have drawn my attention to a phenomenon worth studying; as soon as the density of the water reaches a certain degree the copepod T. fulvus falls into a state of apparent death, from which it can awake even after a very long time and regain normal activity when the water is sufficiently diluted'. The experiments described in this paper were designed to investigate this phenomenon and other reactions of $T$. fulvus to changes in salinity and temperature.

\section{EFFECTS OF SALINITY CHANGES}

T. fulvus were collected from rock pools above high-water neaps at Port St Mary, Isle of Man, and transferred to sea water of salinity $34.0 \%$ in which they were conditioned for 2 days, to overcome the effects of the fluctuations in the salinity of the rock pools. Lower salinities were obtained by diluting the sea water with distilled water and higher salinities were obtained by adding Tidman's sea salt. The salinities were determined by titration with silver nitrate.

A graded series of twenty-three solutions was prepared with salinities ranging from 0.0 to $118.0 \%$. Approximately fifty specimens of conditioned $T$. fulvus were pipetted into 50 c.c. of each solution and left for a period of up to I5 days.

It was found that in distilled water the animals died after $84 \mathrm{~h}$, while in solutions from salinity $4.2 \%$ up to $90.0 \%$ they were living normally after I5 days. In salinities above $90.0 \%$ T. fulvus fell into a state of apparent death, as described by Issel (I9I4); as soon as the animals were introduced into the solutions of salinity above $90.0 \%$ they ceased their activity and sank to the 
bottom of the dish and lay motionless. But when they were transferred back to sea water of salinity $34.0 \%$ they regained their normal activity after a period depending on the strength of the previous solution and the duration of immersion in it.

In order to investigate this behaviour a further series of experiments was conducted. For this a set of four solutions was made with salinities of $98 \cdot 0$, I $35.0,180 \cdot 0$ and $225.0 \%$ respectively. Fifty specimens of conditioned $T$. fulvus were transferred to each of the above solutions. At definite intervals animals were transferred from the high salinity solutions to sea water of salinity $34^{\circ} 0 \%$ and the time taken for complete recovery was noted. The temperature during

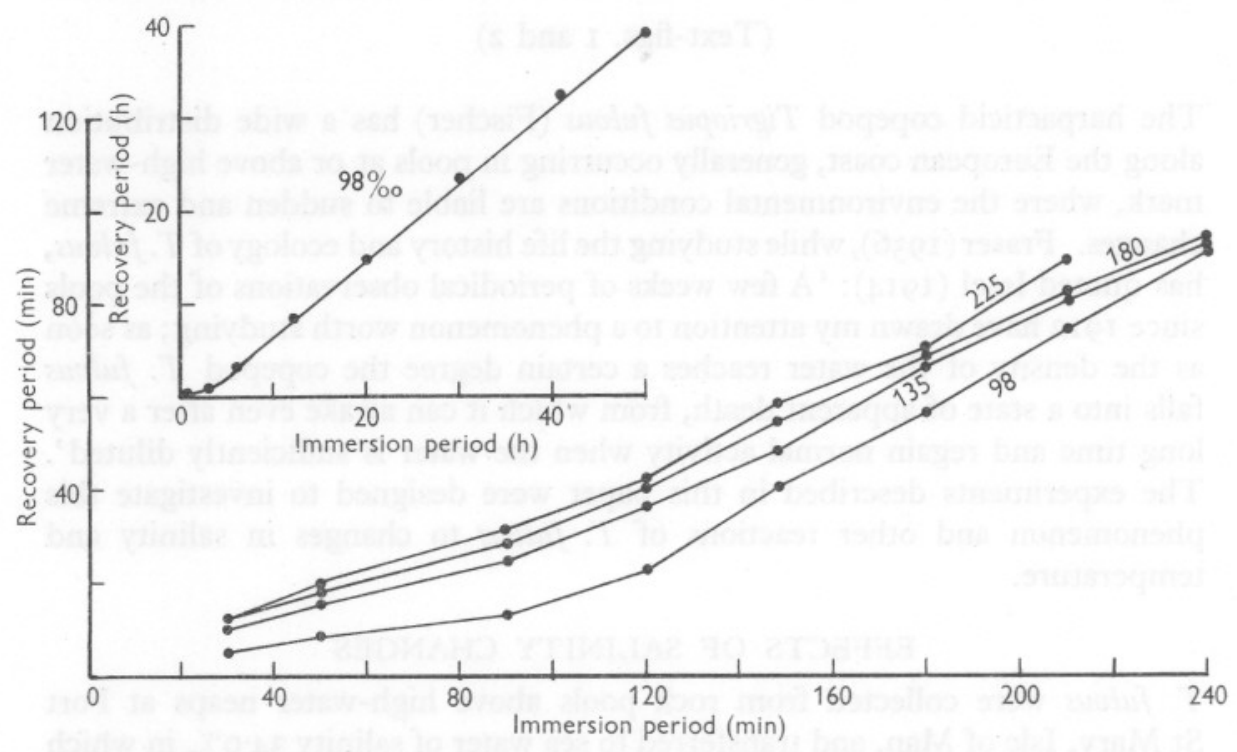

Fig. I. Tigriopus fulvus. Relation between immersion period and the recovery period at salinities of $98,135,180$, and $225 \%$, for various immersion periods up to $4 \mathrm{~h}$. Inset: the same for a salinity of $98 \%$, when the immersion period was taken up to $50 \mathrm{~h}$.

the experiments varied between 16.0 and $18.0^{\circ} \mathrm{C}$. The relation between the immersion period and the recovery period is shown in Fig. I. The points plotted are the means of two experiments; variation between the repeat experiments was very small. It will be seen that the strength of the high salinity solutions had some effect on the period required to regain normal activity after transfer, those which were immersed in stronger solutions requiring a rather longer recovery period. This factor was, however, of much less importance than the immersion period, and in cases of immersion for more than $4 \mathrm{~h}$ may be virtually neglected. The species was found to be unable to survive indefinite immersion in any of the solutions in which the 'apparent death' response was observed, the survival period varying with the salinity. 
The maximum immersion periods, after which no recovery took place, were as follows:

$\begin{array}{ccc}\text { Solution } & \begin{array}{c}\text { Malinity } \\ (\%)\end{array} & \begin{array}{c}\text { Maximum } \\ \text { immersion period } \\ (\mathrm{h})\end{array} \\ \text { I } & 98 & 60 \\ 2 & 135 & 30 \\ 3 & 180 & 30 \\ 4 & 225 & 3\end{array}$

\section{EFFECTS OF TEMPERATURE CHANGES}

Two batches of twenty $T$. fulvus in 20 c.c. of sea water of salinity $34.0 \%$, immersed in a water-bath, were subjected to a slow rise in temperature at the rate of approximately $2^{\circ} \mathrm{C}$ per hour by means of a thermostat and heater. The animals behaved normally up to $34^{\circ} \mathrm{C}$, but their movements became more rapid with increasing temperature until heat coma set in at $36^{\circ} \mathrm{C}$ when they became motionless and sank to the bottom of the dish. Death occurred when

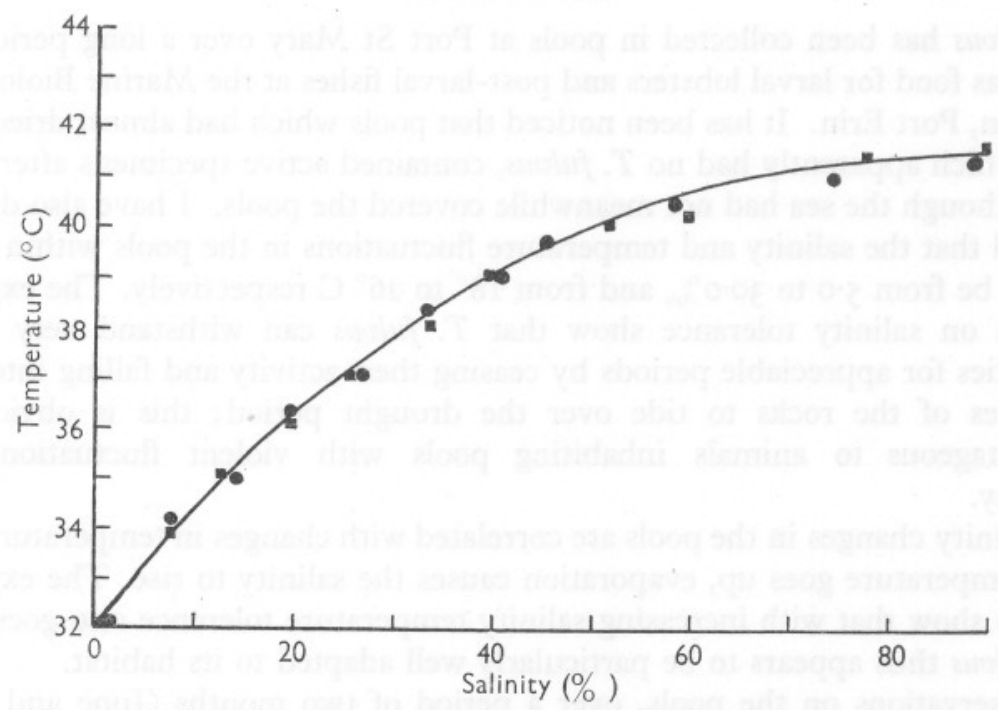

Fig. 2. Tigriopus fulvus. Lethal temperatures at different salinities. - First experiment, I8 August I956. Second experiment, 26 September 1956.

the temperature reached $38^{\circ} \mathrm{C}$. The death-point was determined when no recovery took place after transferring the animals to room temperature $\left(16^{\circ} \mathrm{C}\right)$ for a period of $24 \mathrm{~h}$.

In rock pools at high water, high temperatures are usually accompanied by increasing salinities on account of evaporation. An experiment, therefore, was set up to investigate the relation between the salinity of water and temperature tolerance of $T$. fulvus. 
For this a series of eleven solutions of different salinities ranging from distilled water to $90.0 \%$ were made. Twenty specimens of $T$. fulvus were transferred from sea water to 20 c.c. of each solution in small dishes. These dishes were floated on a water-bath at $16^{\circ} \mathrm{C}$ and the temperature of the bath increased at a rate of approximately $2^{\circ} \mathrm{C}$ per hour. The $T$. fulvus were kept under continuous observation and the temperature of the water in each dish was taken at the 'death point'. This point was remarkably clear-cut, for about three-quarters of the animals always died simultaneously; the rest died within $3 \mathrm{~min}$, during which the temperature never rose more than $\mathrm{O} \cdot \mathrm{I}^{\circ} \mathrm{C}$.

This experiment was repeated a month later with a fresh set of solutions and a new stock of Tigriopus. The second set of results agreed very closely with the first set, and both are shown in Fig. 2, which shows that the lethal temperatures varied over a range of $9.8^{\circ} \mathrm{C}$ depending on the salinity of the solutions. In distilled water death occurred at $32.0^{\circ} \mathrm{C}$, while in salinity $90.0 \%$ the animals died at $4 \mathrm{I} \cdot 8^{\circ} \mathrm{C}$.

\section{DISCUSSION}

T. fulvus has been collected in pools at Port St Mary over a long period to serve as food for larval lobsters and post-larval fishes at the Marine Biological Station, Port Erin. It has been noticed that pools which had almost dried up, and which apparently had no T. fulvus, contained active specimens after rain even though the sea had not meanwhile covered the pools. I have also determined that the salinity and temperature fluctuations in the pools within $24 \mathrm{~h}$ could be from 5.0 to $30.0 \%$ and from $18^{\circ}$ to $26^{\circ} \mathrm{C}$ respectively. The experiments on salinity tolerance show that $T$. fulvus can withstand very high salinities for appreciable periods by ceasing their activity and falling into the crevices of the rocks to tide over the drought period; this is obviously advantageous to animals inhabiting pools with violent fluctuations in salinity.

Salinity changes in the pools are correlated with changes in temperature; as the temperature goes up, evaporation causes the salinity to rise. The experiments show that with increasing salinity temperature tolerance also goes up; T. fulvus thus appears to be particularly well adapted to its habitat.

Observations on the pools, over a period of two months (June and July I956) have shown that the fluctuations in salinity and temperature in the pools were from 5.0 to $42.0 \%$ and $13^{\circ}$ to $27^{\circ} \mathrm{C}$ respectively. These changes are well within the tolerance limits of $T$. fulvus as shown in the foregoing experiments.

I am greatly indebted to $\mathrm{Mr} \mathrm{A}$. B. Bowers for his help in the collections and experimental work. I also wish to thank Mr J. S. Colman and Dr D. I. Williamson for their help in preparing the manuscript. 


\section{SUMMARY}

Tigriopus fulvus can live normally within a salinity range of from 4.2 to $90 \%$. In waters of salinities above $90 \%$ it falls into a state of apparent death from which it can recover if transferred back to lower salinities.

The relation between immersion period and the recovery period is only slightly different at different salinities.

The lethal temperatures vary between 32.0 and $4 \mathrm{I} \cdot 8^{\circ} \mathrm{C}$ depending on the salinity of the sea water, the lethal temperature being higher in higher salinities.

The fluctuations in salinity and temperature in the pools where the animals were collected are well within their tolerance limits.

$T$. fulvus is well adapted to its habitat.

\section{REFERENCES}

FRASER, J. H., I936. The occurrence, ecology and life history of Tigriopus fulvus (Fischer). F. mar. biol. Ass. U.K., Vol. 20, pp. 523-536.

IsseL, R., I9I4. Vita latente per concentraz. dell'acqua e biologia delle pozze de scogliera. Mitt. Zool. Sta. Neapel, Bd. 22, pp. 191-255. 